\title{
Hydro-mechanical behaviour of a sandy silt from a river embankment
}

\author{
Vincenzo Butticè ${ }^{1, *}$, Alessio Ferrari ${ }^{1,2}$, Carmine G. Gragnano ${ }^{3}$ and Guido Gottardi ${ }^{3}$ \\ ${ }^{1}$ Dipatimento di Ingegneria - DI, Università degli Studi di Palermo, 90133 Palermo, Italy \\ ${ }^{2}$ Laboratory of Soil Mechanics - Ecole Polytechnique Fédérale de Lausanne, Switzerland \\ ${ }^{3}$ Dipartimento di Ingegneria Civile, Chimica, Ambientale e dei Materiali - DICAM, Università di Bologna, 40126 Bologna, Italy
}

\begin{abstract}
The paper presents the results of an experimental campaign aimed at characterizing the hydromechanical behaviour of a sandy silt from a river embankment. Due to continuous river level fluctuations and changing climatic and environmental conditions, flood embankment materials experience frequent variations in degree of saturation and suction values. Such variations strongly impact the earthwork performance both in terms of seepage and stability conditions. For these reasons, a detailed characterization of the material behaviour in unsaturated conditions was carried out. Experiments were designed in order to highlight the response of the involved soil in terms of changes in matric suction and confining stress. All tests were performed on undisturbed samples from the embankment. To cover the suction range, which is expected to be significant for the material and assessed through field monitoring, a combination of several suction-control and suction-measurement techniques was used (e.g. negative water column, axial translation, tensiometers). Obtained results enabled (i) to quantify the evolution of the yield stress with suction, (ii) to assess the collapse upon wetting behaviour, (iii) to get detailed information on the water retention behaviour and (iv) to define the relative permeability of the soil. This extensive characterization work serves as a basis for the analysis of the embankment response following river level variations, the final purpose of the research being to establish a reliable methodology and a feasible procedure for the realistic assessment of the safety margins under transient seepage.
\end{abstract}

\section{Introduction}

River embankments are used to protect land, flood plains and humans from river flooding. As all earthen infrastructures, they are generally in unsaturated conditions. The degree of saturation and the suction could fluctuate as a result of river level variation and rainfall. The seepage and the stability of the embankments are strictly linked to these variations.

Despite these evidences there is a limited experience to perform safety assessment of river embankments in unsaturated conditions. Also, very few experimental evidences are available on the unsaturated behaviour of undisturbed soil samples from the embankments.

With the aim to highlight possible effects of partial saturation on the riverbank filling materials, this work presents selected results from an experimental investigation of a sandy silt at different levels of matric suction. The experimental programme was designed and carried out in order to define the hydro-mechanical behaviour of the soil when subjected to change in matric suction and vertical stress.

To cover the suction range relevant for the soil, a combination of several suction-control and suctionmeasurement techniques was used. Suction-controlled oedometric tests were performed in order to describe the evolution of the yield stress and soil stiffness with suction, and to determine the position of the LoadingCollapse curve (LC). The monitoring of the pore water volume changes induced by the suction changes allowed assessing the permeability function of the material. All tests were performed on undisturbed samples from an experimental site where recent studies have provided data on the hydraulic response of a river embankment $[1,2]$ towards hydrometric fluctuations and atmospheric loadings. This extensive characterization work serves as a basis for the analysis of the embankment response under severe variations of river level and rainfall with high intensity, to evaluate the safety margins under transient seepage and the collapsibility of the river embankment.

\section{Materials and methods}

\subsection{Embankment features}

The experimental site is located on a river embankment in Northern Italy [3]. The cross section of the riverbank considered in this work has a $11 \mathrm{~m}$ high crown, referred to the ground level. Riverside and landward slopes are $30^{\circ}$ and $25^{\circ}$, respectively and the embankment crest is

Corresponding author: vincenzo.buttice@unipa.it 
$4.6 \mathrm{~m}$ wide. On the river side there is a berm about $5.5 \mathrm{~m}$ wide and generally rich in vegetation. Several tests were carried out in order to characterize in detail the soil both from the hydraulic and mechanical points of view. A set of four CPTU tests were performed in the area, two from the crest and two from the berm, along two adjacent cross sections, enabling to identify the embankment stratigraphy and a preliminary mechanical characterization. Test results have shown that the embankment filling material mostly consists of alternating silt and sandy silt; boreholes have been also carried out for undisturbed soil sampling and installation of sensors for the monitoring of soil suction and water content at various depths in the berm and in main embankment [4].

\subsection{Characterization of tested soil samples}

The void ratio determined from soil samples is in the range of $0.74-1.24$. The specific gravity is $G_{s}=2.73 \pm$ 0.01 . The grain size presents a sand size fraction variable from 50 to $68 \%$, the silt accounts for 22 to $30 \%$, while the overall embankment soil has been classified as a sandy silt. The clay fraction is around $9 \%-14 \%$. Field measurements have shown that the suction range experienced by the soil in the embankment is in the range of $10-50 \mathrm{kPa}$, but shallow measurements (beneath the first $1.5 \mathrm{~m}$ of depth) may also reach thousands of $\mathrm{kPa}$.

The water retention behaviour was analysed with a combination of different suction-control and suctionmeasurement techniques (i.e. negative water column, axial translation, tensiometer, filter paper). During the tests the deformations of the samples were monitored using different measuring instruments (i.e. caliper, micrometer, dial gauge) in order to trace the evolution of void ratio and to compute the degree of saturation. Fig. 1 shows the measured main drying and main wetting curves. The experimental points on the plane $\left(\mathrm{S}_{\mathrm{r}}, \mathrm{s}\right)$ were fitted using the expression proposed by [5]:

$$
S_{r}=S_{r, r e s}+\frac{1-S_{r, r e s}}{\left[1+(\alpha s)^{n}\right]^{m}}
$$

where $S_{r, \text { res }}$ is the residual degree of saturation, and $\alpha, n$ and $m$ are fitting parameters (Table 1). The initial suction of the samples was $30 \mathrm{kPa}$ (measures provided by means a tensiometer). A limited hysteretic behaviour was observed during wetting and drying paths. The main drying curve suggests that the air-entry value is approximately $4.2 \mathrm{kPa}$.

\subsection{Controlled-suction oedometric tests}

In order to determine the volumetric response of the soil of the river embankment when it is subjected to variation of the degree of the saturation, two controlled-suction tests and one conventional oedometric test were carried out.

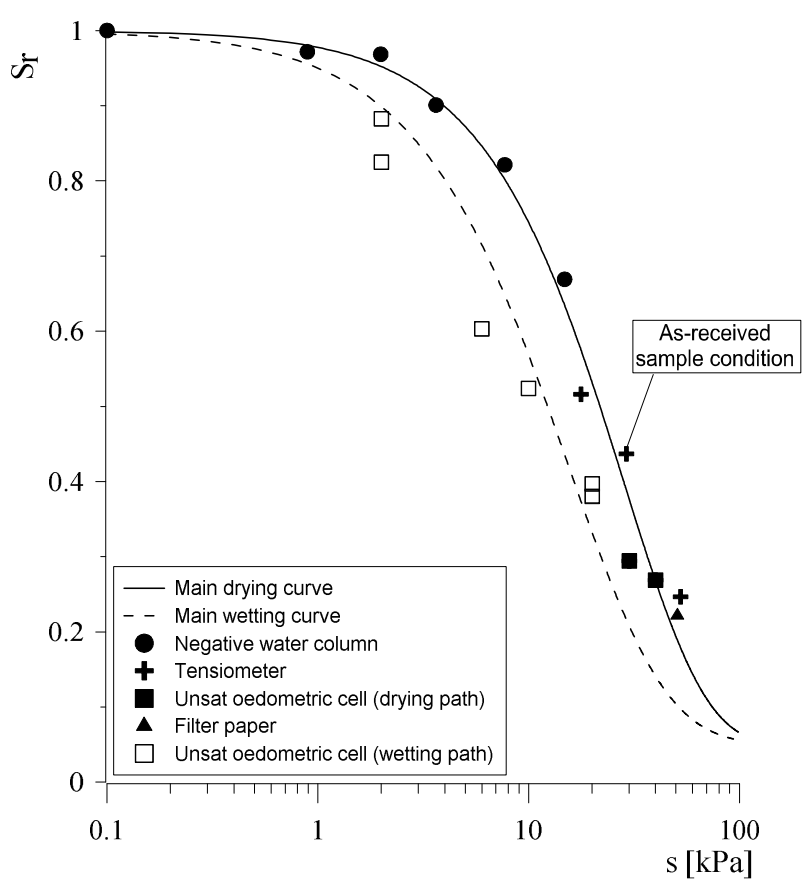

Fig. 1. Soil water retention curves.

The two controlled-suction tests were carried out in a controlled-suction oedometric cell operating with the Axial Translation Technique (ATT) on specimens with a diameter of $50.0 \mathrm{~mm}$ and a height of $20.0 \mathrm{~mm}$. The suction was imposed by setting constant pore air pressure $\left(u_{a}\right)$ at the top base of the specimen and varying the water pressure $\left(u_{w}\right)$ at the bottom of the specimen through a high air entry value porous disc (air entry value equal to $1500 \mathrm{kPa}$ ). The pore water volume changes were measured by means of a burette and the measurements were corrected to take into account the air diffusions through and water evaporation from the ceramic disc [6].

The stress paths followed in the controlled-suction oedometer are reported in the plane "vertical net stress (difference between the total vertical stress and the pore air pressure) vs. suction" in Fig. 2.The stress path depicted in Fig. 2(a) was planned in order to determine the parameters of the Barcelona Basic Model (BBM) [7] using only one test. After a first equalization to a suction of $40 \mathrm{kPa}$, a first loading - unloading path (B-C-D) was performed to assess the initial position of the $\mathrm{LC}$ and the values of the elastic stiffness parameter and stiffness parameter for the virgin state.

Table 1. Parameters for water retention curves.

\begin{tabular}{|c|c|c|}
\hline Parameter & $\begin{array}{c}\text { Main } \\
\text { drying }\end{array}$ & $\begin{array}{c}\text { Main } \\
\text { Wetting }\end{array}$ \\
\hline$\alpha\left[\mathrm{kPa}^{-1}\right]$ & 0.005 & 0.010 \\
\hline $\mathrm{n}$ & 1.00 & 1.06 \\
\hline $\mathrm{m}$ & 6.13 & 7.31 \\
\hline $\mathrm{S}_{\mathrm{r}, \mathrm{res}}$ & \multicolumn{2}{|c|}{0.03} \\
\hline
\end{tabular}




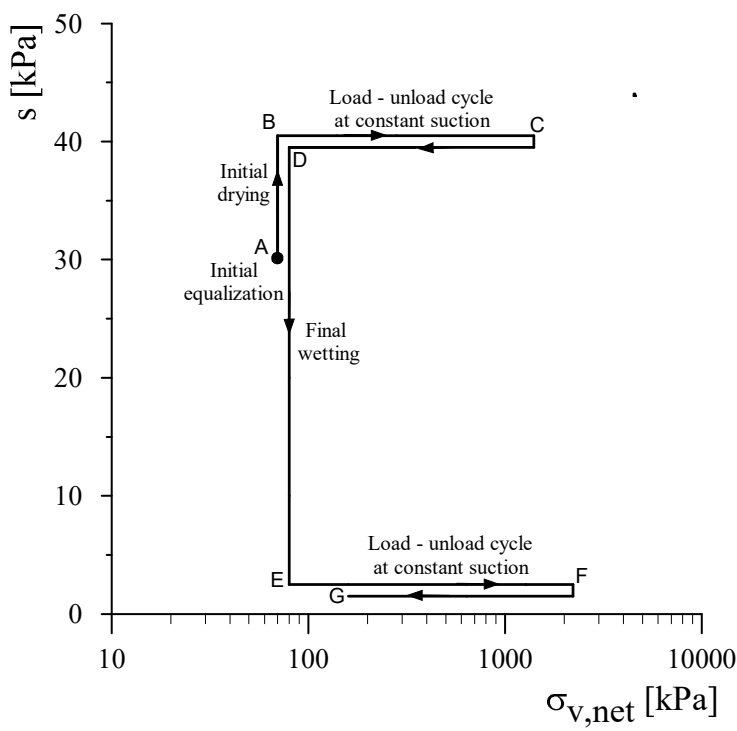

(a)

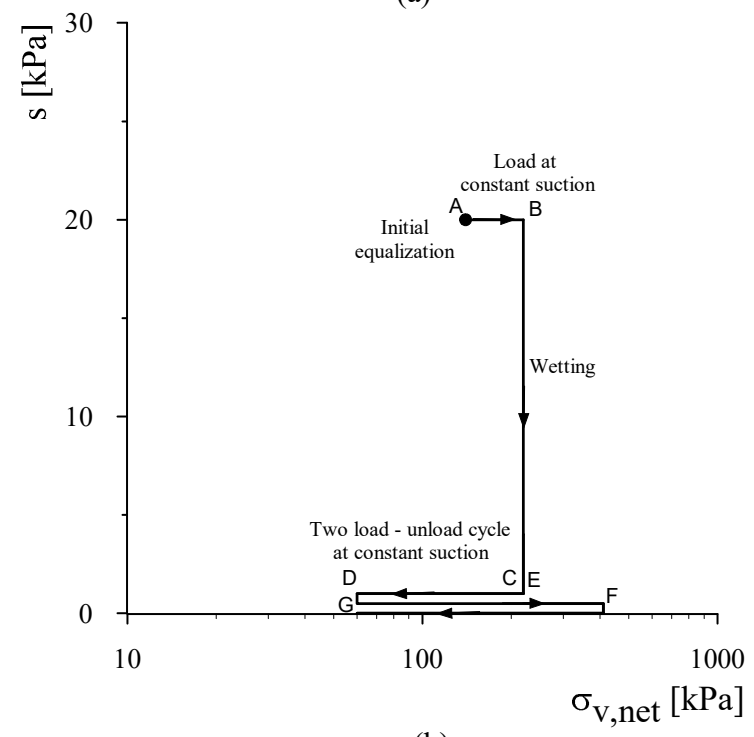

(b)

Fig. 2. Stress paths used in the controlled-suction oedometric tests.

The wetting path (D-E) was performed at low value of vertical net stress in order to prevent plastic deformations.

The last loading - unloading path (E-F-G) was done to determine the yield stress and the compressibility index at $2 \mathrm{kPa}$ of suction after the previous yielding, and to define the LC curve in the final position. The results of this test and the results of the conventional oedometric test were allowed to calibrate the parameters of the BBM model.

In the second test Fig. 2(b), the suction reduction at constant vertical net stress was carried out to assess the collapse upon wetting behaviour (B-C).

Information on pore water volume variations induced by suction changes in both tests allowed to define the relative permeability of the soil.

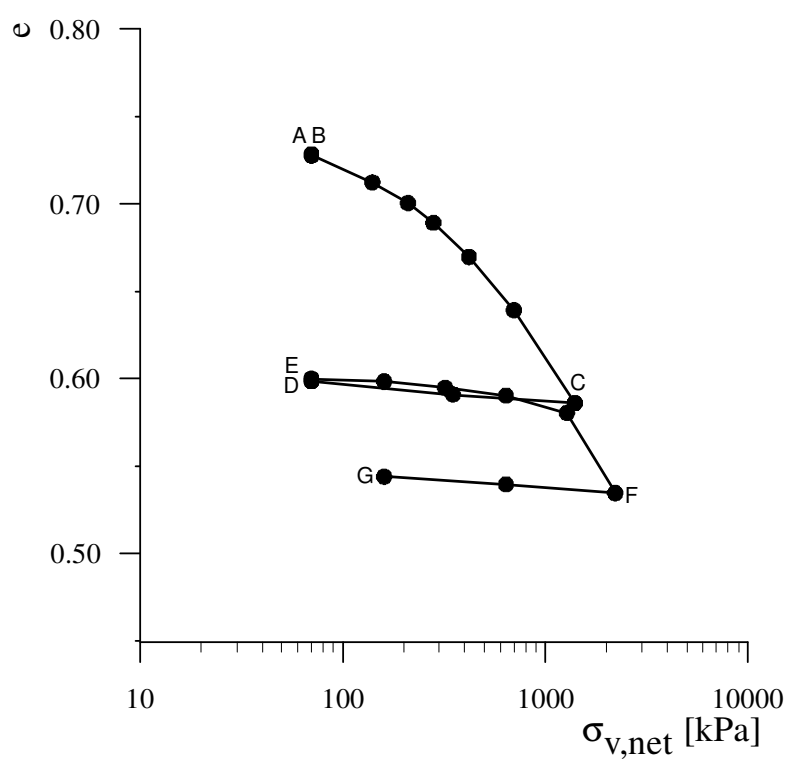

(a)

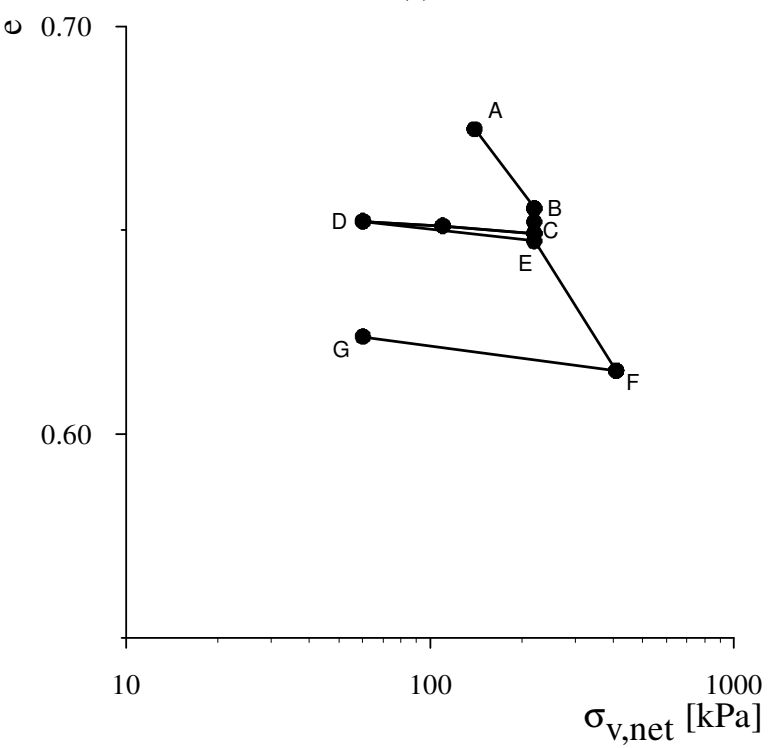

(b)

Fig. 3. Results of the controlled-suction oedometric tests following the stress paths in Fig. 2.

\section{Tests results}

\subsection{Elasto-plastic volumetric response}

Figure 3(a) depicts the results for the stress paths shown in Fig. 2(a). During the initial drying, no significant deformation of the specimen was recorded. The first loading path (B-C) at constant suction ( $\mathrm{s}=40 \mathrm{kPa})$ highlighted the transition from a pre-yield to a postyield behaviour. In addition, a new yield point of the LC in its final position is imposed (point $C$ ).

The unloading path (C-D) allowed to determine the elastic response of the material. During the wetting (DE) no deformations were recorder.

The final loading - unloading path (E-F-G) shows the yielding at low value of suction $(2 \mathrm{kPa})$, and then a second point of the LC in the final position. The final unloading (F-G) at suction of $2 \mathrm{kPa}$ followed a similar trend with respect to unloading at a suction of $40 \mathrm{kPa}$, 
showing that the elastic response may be considered independent of the applied suction.

Figure 3(b) depicts the results obtained for the stress path depicted in Fig. 2(b). The loading path (A-B) caused the yielding of the soil and the normal compression line was reached. During the wetting path (B-C) the suction changed from $20 \mathrm{kPa}$ to 0 and a reduction in void ratio was registered. This reduction of the pore volume is a result of the collapse upon wetting behaviour. The successive unloading - loading path $(\mathrm{C}$ D-E-F) confirms the new yield point caused by the previously wetting. The LC curve is defined, in the plane vertical net stress against suction, as follows:

$$
\frac{\left(\sigma_{v, \text { net }}\right)_{s}}{\sigma^{c}}=\left[\frac{\left(\sigma_{v, \text { net }}\right)_{0}^{*}}{\sigma^{c}}\right]^{[\lambda(0)-k] /[\lambda(s)-k]}
$$

where $\left(\sigma_{v, \text { net }}\right)_{0}^{*}$ is the yield stress at zero suction, $\sigma^{c}$ is a fitting parameter, $k$ is the elastic stiffness parameter and $\lambda(0)$ is the stiffness parameter for virgin state at zero suction. The increase in soil stiffness with suction is expressed as follows:

$$
\lambda(s)=\lambda(0)\left[(1-r)^{-\beta s}+r\right]
$$

where $r$ is a parameter related to the maximum stiffness of the soil, and $\beta$ is a constant which controls the rate of increase of soil stiffness with suction. Figure 4 depicts the increase of the stiffness parameter for virgin state with the suction.

Figure 5 shows the LC curve pre and post-yielding. As explained before, stress path of Fig. 2(a) has been designed to determine all of the parameter needed for the model. Whether the yield stress obtained from suctioncontrolled oedometric test and the yield stress obtained from conventional oedometric tests cannot univocally define the LC curve shape in the initial position, it is possible to define the elastic domain for the undisturbed specimen starting from its yielding condition, knowing three points (two derived from the test depicted in Fig 2.(a), and one from the saturated test):

- the new yield stress, imposed in the stress path at $\mathrm{s}=40 \mathrm{kPa}$ (point $\mathrm{C}-$ Fig. 2(a));

- yield stress of LC curve in the final position, obtained during the loading path (E-F - Fig. 2(a));

- the saturated yield point of the LC curve in the final position, obtained by the Virgin Compression Line for the same void ratio $\left(\sigma_{v, n e t}\right)_{0, f}^{*}$;

it is possible to define the LC shape in its final position.

The LC curve in the initial position is therefore obtained knowing the hardening laws of the model [7], the yield stress in saturated condition and the yield stress obtained during the loading path $\mathrm{B}-\mathrm{C}$ depicted in Fig. 2(a). Table 2 reports the parameter of the model.

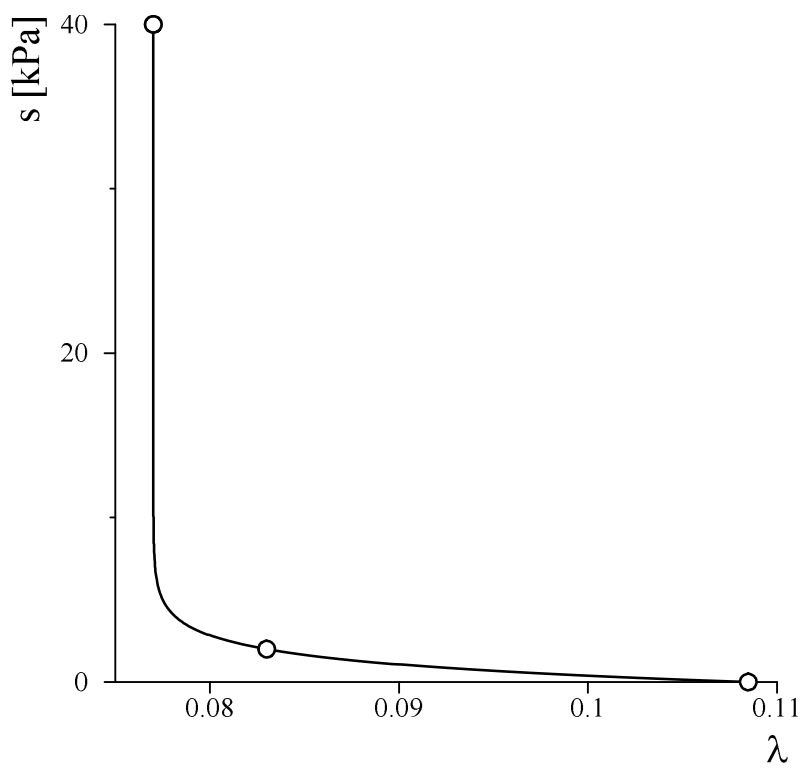

Fig. 4. Stiffness parameter for virgin state vs. suction.

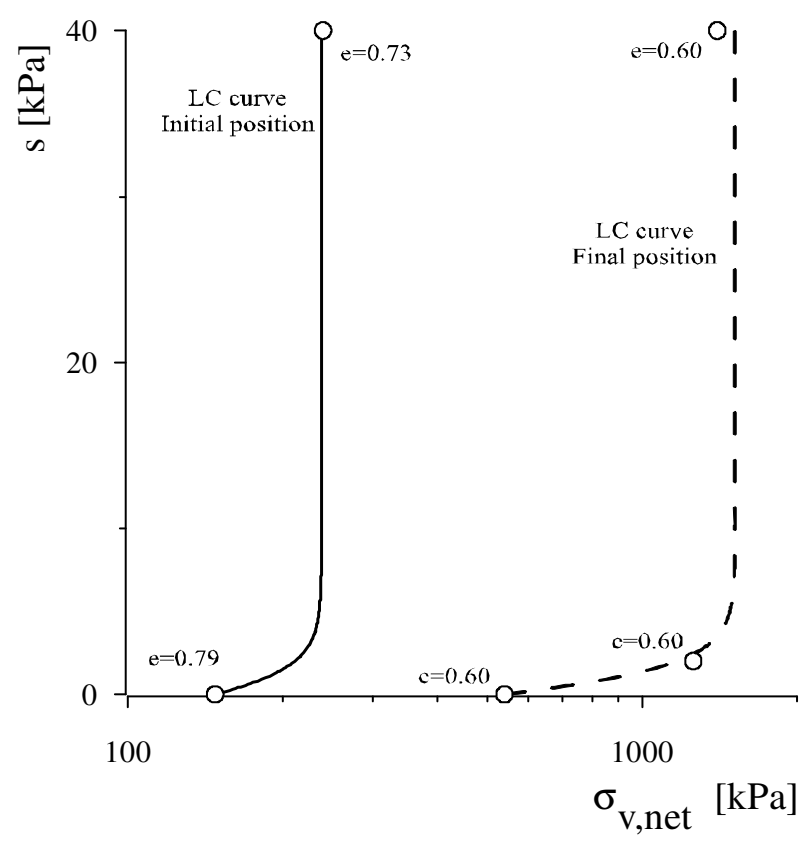

Fig. 5. Loading - Collapse curve, pre-yielding and postyielding.

\subsection{Relative permeability function}

The registration of pore water volume changes allowed determining the permeability function of the material.

The hydraulic conductivity values were obtained from both wetting and drying paths, and the measured volumes were corrected to take into account the air diffusions through and water evaporation from the ceramic disc [6].

The total amount of intruded/extracted water in a suction step was expressed as follows [8]:

$$
V_{w}(t)=\left[1-\sum_{n=1}^{\infty} \frac{2 \exp \left(-\alpha_{n}^{2} D_{w} t / L^{2}\right)}{\alpha_{n}^{2}\left(A+\csc ^{2} \alpha_{n}\right)}\right] V_{0}
$$


where $V_{0}$ is the total volume exchanged for a water pressure increment/decrement, $V_{w}$ the total volume exchanged at any time, $L$ the specimen height, $A$ the ratio of impedance of the ceramic disc to the impedance of the soil $A=z_{m} / z_{s}=k_{w} e /\left(L k_{d}\right)$ (where $e$ is the thickness of the ceramic disc and $k_{d}$ its water permeability), and $\alpha_{n}$ the $n^{\text {th }}$ solution of the equation $A \alpha_{n}=\cot \alpha_{n}($ for $\mathrm{n}=1,2, \ldots)$.

The water permeability $k_{w}$ is calculated from the following expression $[9,10]$ :

$$
k_{w}=\frac{D_{w} \gamma_{w} V_{0}}{V \delta_{w}}
$$

where $V$ is the volume of the specimen. The experimental points were interpolated used the following equation:

$$
k_{w}\left(S_{r}\right)=k_{w, \max }\left(\frac{S_{r}}{S_{r, \max }}\right)^{\zeta}
$$

where $k_{w, \max }$ is the maximum value of the hydraulic permeability registered, and $S_{r, \max }$ is the correspondent value of the degree of saturation. $\zeta$ is a fitting parameter. The maximum value of the water permeability was carried out by mean of a conventional oedometric test in saturated condition $\left(k_{w, s a t}=1.310^{-7}[\mathrm{~m} / \mathrm{s}], S_{r, \text { max }}=1\right)$.

The best-fitted value $\zeta$ was 6.2 . Figure 6 shown the measured values along with the fitted permeability function.

\section{Summary and conclusion}

The safety assessment of river embankments requires to consider the relevant effect of changes in suction and degree of saturation of the involved soils.

This paper has shown how, with a limited number of tests (two controlled-suction oedometric tests and one conventional oedometric test), it is possible to derive a comprehensive understanding of the elasto-plastic volumetric behaviour of the soil.

Table 2. Parameters of the elasto-plastic model.

\begin{tabular}{|c|c|}
\hline Parameter & Value \\
\hline$r$ & 0.709 \\
\hline$\beta$ & 0.828 \\
\hline$\lambda(0)$ & 0.108 \\
\hline$\sigma^{c}[\mathrm{kPa}]$ & 60 \\
\hline$\left(\sigma_{v, \text { net }}\right)_{0}^{*}[\mathrm{kPa}]$ & 148 \\
\hline$\left(\sigma_{v, \text { net }}\right)_{0, f}^{*}[\mathrm{kPa}]$ & 530 \\
\hline
\end{tabular}

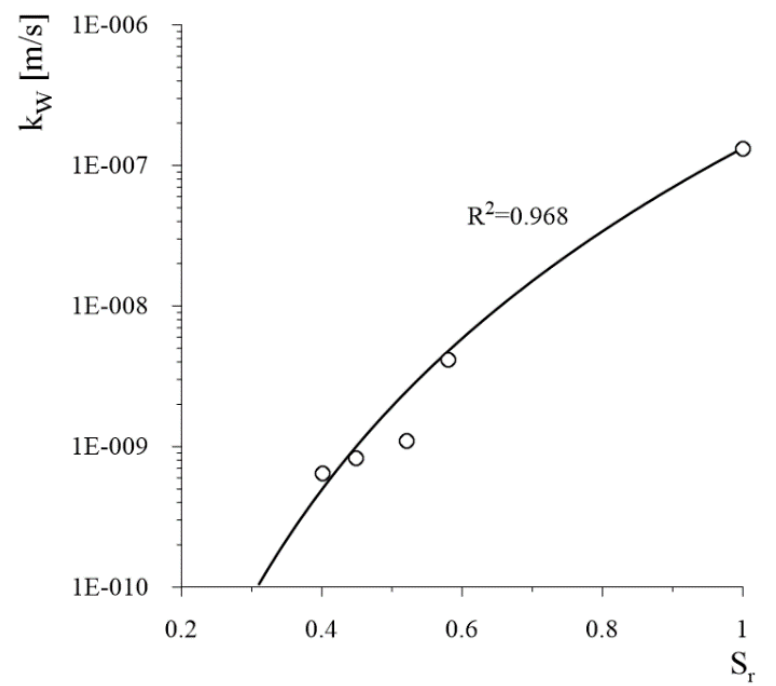

Fig. 6. Water permeability vs. degree of saturation.

The suction controlled oedometric tests enabled to assess the collapse upon soil wetting. In fact, the tested sandy silt has shown typical features of collapsible soils. In addition, the evolution of the yield stress with suction was quantified and the results allowed the calibration of a constitutive model for unsaturated soils.

To determine the hydraulic soil behaviour, various experimental techniques were used, in order to cover different ranges of suction. The study of the water retention behaviour showed limited hysteretic effect and a negligible related dependence on the void ratio. Permeability coefficient at different degrees of saturation has been determined measuring exchanged water volume during the wetting paths of the oedometric tests. Results show that the permeability tends to be very low when the degree of saturation is in the range of what typically measured in the field, but also that it rapidly increases with the degree of saturation.

In conclusion, despite the soil of the river embankment tested in this work have proved to be potentially collapsible, the low water permeability tends to limits water content increase within the embankment. In this way the degree of saturation of the filling material is expected to undergo limited variations with the river level and only severe and persistent hydrometric peaks in association with heavy rainfalls could cause collapse upon wetting.

However, the findings of this study are particularly significant for a proper interpretation of site measurements (suction and water content monitoring) and for a reliable evaluation of the riverbank safety margins with river water level fluctuations under transient flow conditions.

\section{References}

1. C.G. Gragnano, G. Gottardi, M. Moscariello, S. Cuomo, I. Rocchi, $7^{\text {th }}$ Inter. Conf. Unsat. Soils (2018)

2. G. Gottardi, C.G. Gragnano, I. Rocchi, M. Bittelli, Procedia Engineering. 158, 350-355 (2016) 
3. I. Rocchi, C.G. Gragnano, L. Govoni, A. Mentani, M. Bittelli, P. Castiglione, O. Buzzi and G. Gottardi, Geotechnical Research 5, 1, 1-10 (2018)

4. C.G. Gragnano, I. Bertolini, I. Rocchi, and G. Gottardi, 7th Italian National Congress of Geotechnical Researchers, (2019)

5. M.T. Van Genuchten, Soil Sci. Soc. Am. J. 44, 5 (1980)

6. C. Airò Farulla, A. Ferrari, International symposium on advanced experimental unsaturated soil mechanics (eds. A. Tarantino, E. Romero and Y. J. Cui) London, UK: Taylor \& Francis Group, 43-48 (2005)

7. E.E. Alonso, A. Gens, A. Josa, Geotechnique 40, 3 (1990)

8. R.J. Kunze, D. Kirkham, Soil Sci. Soc. Am. Proc. 26, 421-426 (1962)

9. E. Romero, E.E. Alonso, J. Knodelsdorf, NAGRA Project Report 02-05. Wenningen, Switzerland: NAGRA (2002)

10. A. Ferrari, J. Eichenberger and L. Laloui, Geotechnique 63, 11, 1433-1446 (2013) 